$$
\begin{aligned}
& \text { SANO96-13810 } \\
& \text { CONF-961092--1 }
\end{aligned}
$$

\title{
PAMTRAK: A System to Monitor High Value Objects and Personnel in Restricted Areas
}

\author{
DeNise A. Anspach \\ Sandia National Laboratories \\ P.O. Box 5800 MS 0761 \\ Albuquerque, NM 87185 \\ (505) 844-8088 \\ Jonathan P. Anspach \\ AlliedSignal Kansas City Operations \\ P.O. Box 4339 Sta. A. \\ Albuquerque, NM 87196 \\ (505) 844-6884
}

\begin{abstract}
The United States Department of Energy (DOE) uses sensitive or classified parts and material that must be protected and accounted for. We believe there is a need for an automated system that can help protect and monitor these parts and material. In response to this need Sandia National Laboratories (SNL) has developed a real-time personnel and material tracking system called PAMTRAK that has been installed at selected DOE facilities. ${ }^{1}$ PAMTRAK safeguards sensitive parts and material by tracking tags worn by personnel and by monitoring sensors attached to the parts or material.
\end{abstract}

This paper describes our goals when designing PAMTRAK, the PAMTRAK system components, our current installations, and the benefits a site can expect when using PAMTRAK.

So far PAMTRAK has been installed exclusively at government facilities; however, it is also applicable to private industries that need to protect high value assets. Through government programs such as CRADAs, SBIRs, and other mechanisms, the DOE often works with private industry to promote further development and commercialization of national laboratory developed technologies. SNL supports and welcomes partners and new users of PAMTRAK.

1 This work was supported by the United States Department of Energy under contract DE-AC0494AL85000.

\author{
B. Gail Walters \\ Argonne National Laboratory-West \\ P.O. Box 2528 \\ Idaho Falls, ID 83403-2528 \\ (208) 533-7044
}

Dr. Berry Crain, Jr.

Science Applications International Corporation

Savannah River Site

Aiken, SC 29808

(803) $725-7339$

\section{DESIGN GOALS}

Our goals when designing PAMTRAK were to:

- Provide a high degree of confidence that sensitive material is being protected by reporting, in a timely manner, any unauthorized movements of personnel or material,

- Minimize the impact on plant operations,

- Be able to communicate with a facility's existing systems, resulting in an integrated safeguards and security system,

- Produce a robust system that will operate for years with minimal maintenance,

- Be comprehensive and flexible enough to be used in many facilities without modification,

- Be relatively inexpensive for sites to install and maintain, and

- Be usable in either static or active environments.

\section{SYSTEM DESCRIPTION}

The PAMTRAK system incorporates a variety of sensor subsystems, each offering different techniques to monitor material and track personnel (see Figure 1). A site can choose to use any subsystem or combination of subsystems that PAMTRAK supports. 


\section{DISCLAIMER}

Portions of this document may be illegible in electronic image products. Images are produced from the best available original document. 


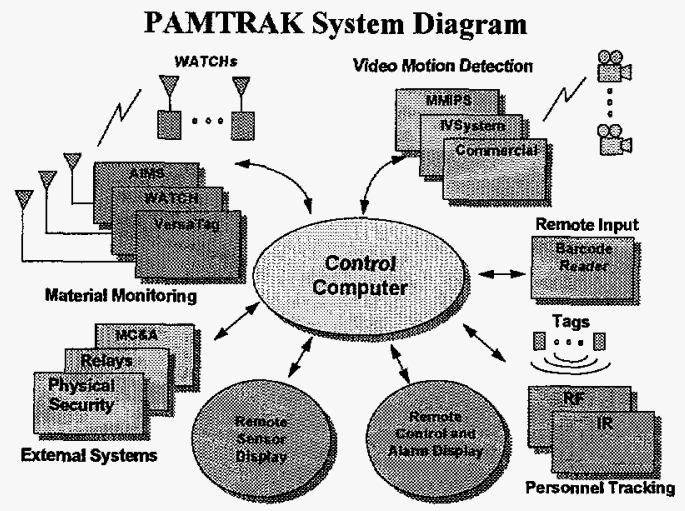

Figure 1

The subsystems are integrated with a PAMTRAK computer that records events, enforces rules pertaining to those events, and interfaces with other external systems, such as material control and accountability (MC\&A) and perimeter security systems.

PAMTRAK incorporates a comprehensive set of security rules from which a site selects those it wants to enforce. The rules to be enforced are stored in a site-specific security rule database. Event reports from the subsystems to the PAMTRAK computer (such as sensor movement or personnel tracking badge location) do not automatically result in alarms. The PAMTRAK computer evaluates the reports as they are received against the user-defined, sitespecific security rule database. If any reported condition violates the security rules, the PAMTRAK computer generates an alarm. As a result, we can install PAMTRAK in a variety of sites with widely differing requirements without having to make modifications to the system software.

\section{Central Computer and Peripherals}

PAMTRAK runs on an IBM-compatible personal computer. To keep costs down we use existing technologies and commercial products whenever possible.

The PAMTRAK computer receives information from the users either directly, through barcode readers, or through remote display/control computers (described below), and the various subsystems, and uses the information to maintain an internal representation of the state of the facility. It compares the state against the rules specified for the site and reports any violations of the rules on the system console or at optional remote control/alarm display computers.

\section{Remote Barcode Readers}

PAMTRAK accepts input from barcode readers to support sites that wish to place barcodes on sensitive parts, material containers, and sensors. The barcode readers allow users to perform a subset of transactions, such as shipping and receiving material, or adding material-monitoring sensors, from remote locations using barcodes to specify the relevant items.

\section{Remote Display/Control Computers}

In addition to the main PAMTRAK computer, a site can install auxiliary computers in other locations to configure and control the PAMTRAK computer, and to display alarms.

We have also developed a material attribute display program, named Keyhole, to graphically depict material attribute measurements, such as weight, temperature, and radiation emission. Keyhole can display past sensor data archived by PAMTRAK, or a continuous, real-time feed of sensor data supplied by PAMTRAK. Keyhole can run on the same computer as PAMTRAK, or on another computer via a dialup or network connection to the PAMTRAK computer.

\section{Sensor Subsystems}

PAMTRAK incorporates a number of sensor and control subsystems that offer a variety of techniques to monitor material and track personnel. A site can choose to implement any combination of these subsystems.

\section{Wireless Motion-Sensing Devices}

The Wireless Alarm Transmission of Container Handling (WATCH) subsystem employs motion sensors packaged together with radio-frequency (RF) transmitters to report attempts to move material. The sensors (known as WATCHs) are placed on material to detect any attempted movement of the material. A WATCH contains a switch that generates a tamper when opened, and periodically sends a state-of-health message so PAMTRAK can detect any attempt to destroy or shield it. 
The Authenticated Item Monitoring (AIMS) subsystem is similar to the WATCH. AIMS starts with the basic WATCH sensor and adds authentication features to reduce the possibility of counterfeit messages. Like WATCHs, AIMS sensor/transmitters are attached directly to the material being monitored.

To overcome some of the drawbacks of the WATCH and AIMS subsystems we also support a subsystem that uses polled RF tags. The VersaTag subsystem's chief differentiating feature is that it sequentially polls the transmitters in order to minimize transmission collisions. It also has the potential to be more effective than the WATCH or AIMS subsystems because it can support material attribute-measuring sensors, such as weight, temperature and radiation emission.

\section{Video Motion Detection}

PAMTRAK supports one or more of the following video subsystems for material monitoring.

The Image Verification System (IVSystem) is a video motion detection (VMD) system developed by Los Alamos National Laboratory. It was designed to monitor inactive storage vaults; therefore, it is very sensitive to minute changes in an image. This sensitivity is user-adjustable.

The TSI $20 / 20$ is a commercial VMD system. Like the IVSystem, it can be used in static areas, such as inactive vaults. It can also adapt to lighting changes and shadows so that it can be used in active work areas without generating excessive false alarms. The TSI $20 / 20$ has a feature that allows a user to define a sequence of regions of interest. It will then report movement only if it detects movement in all of those regions in the correct sequence.

The Material Monitoring Image Processing System (MMIPS) was developed by SNL through funding by the DOE Office of Safeguards and Security. As with the other two systems, the MMIPS can be used in static areas. However, it can also adapt to lighting changes like the TSI 20/20. Like the IVSystem and the TSI 20/20, the MMIPS can process independent video images. However, it also has a feature that allows it to use multiple cameras to create a three-dimensional detection volume around a material, rather than just a two-dimensional detection plane used by the other VMDs. In such a configuration the MMIPS only reports a movement alarm if it detects movement within the volume. This allows workers to move among and around the material without causing alarms. However, if the workers try to touch the material they will penetrate the surface of the volume and trigger an alarm.

\section{Personnel Tracking}

We have two wireless personnel tracking subsystems available to track workers as they move through a site. A personnel tracking subsystem consists of battery-powered tags emitting various types of signals, and associated receivers. Users place the receivers at strategic locations throughout a facility. As workers move about the facility the receivers detect the tags they are wearing and report their locations to the PAMTRAK computer. PAMTRAK uses this information to report unauthorized access to restricted areas, and to enforce site rules (such as the two-person rule).

The Indala System consists of battery-powered, electrostatic proximity tags worn by personnel and exciter/receiver antenna pairs. The antenna pairs have a detection range of approximately eight feet. When the tag enters an exciter field it transmits an RF message that contains a unique ID code. An adjacent receiver antenna detects these messages and sends them to the PAMTRAK computer.

Another personnel tracking system, sold by Precision Tracking FM, Inc., uses tags that emit infrared (IR) signals. These signals are detected by receivers mounted in the ceiling.

\section{External System Interface}

PAMTRAK provides a simple, flexible communications interface between it and other systems a site may have, such as physical security and material control and accountability.

This interface consists of ASCII messages transmitted between the systems over a network or an RS-232 serial line. A user can define all of the applicable communication protocol parameters. PAMTRAK supports three formats: raw ASCII text, a send-and-wait protocol with simple error detection, and a special format to communicate with PCDYMAC, the material control and accountability system used at Argonne National Laboratories - West (ANL-W). Other formats can be added as necessary. 
Outgoing messages, (those from the PAMTRAK computer to an external system), can be either an alarm or transaction report. PAMTRAK can send messages to external systems whenever an alarm occurs or a user enters a transaction, such as shipping a material.

All messages are completely user-definable. They can include static text and replaceable parameters. Different messages can be defined for each external system and for each alarm or transaction.

\section{INSTALLATIONS}

This section describes the PAMTRAK installations. We currently have two demonstration installations: one at SNL's Cooperative Monitoring Center (CMC), and the other at ANL-W's Fuel Manufacturing Facility (FMF). We have also installed PAMTRAK in K-Area at the Savannah River Site as a production system.

\section{Cooperative Monitoring Center (CMC)}

The $\mathrm{CMC}$ is the primary demonstration facility for PAMTRAK at SNL. As such, it incorporates most of the supported subsystems on a small scale. It is available for demonstrations on short notice.

\section{Fuel Manufacturing Facility (FMF)}

The PAMTRAK system is part of the Argonne Unified System (ARGUS) used for Material Control and Accountability (MC\&A) in the Fuel Manufacturing Facility (FMF) at Argonne National Laboratory - West (ANL-W).

All workers entering the FMF must receive an ARGUS badge at the security building. The ARGUS badge contains a picture of the worker, a barcode of the worker's PAMTRAK/PC-DYMAC user identification number, and an attached Precision Tracking FM, Inc. infrared transmitter. Located in the security building is a barcode reader and printer connected to PAMTRAK. Before handing out the worker's badge, the Security Police Officer (SPO) scans the barcode on the badge. This action logs the worker's name and entry time and date into the PAMTRAK system. All access to nuclear material in the FMF must be made by qualified fuel handlers, and the fuel handler must be physically present in the building. When a worker leaves the facility, the ARGUS badge is returned to the SPO and the barcode is scanned, removing the worker from the FMF occupancy list maintained by PAMTRAK. Also, by scanning a barcode transaction sheet, the SPO can generate an activity report of the facility and a list of personnel currently in the facility. PAMTRAK will also generate a building maximum occupancy warning that is printed in the security building.

PAMTRAK is also used to track, apply and remove the material monitoring WATCHs. The WATCHs are used in the storage vault and are attached directly to storage containers that contain nuclear material. Part of the test and evaluation is to demonstrate the WATCH as a Tamper Indicating Device (TID).

The Material Monitoring Image Processing System (MMIPS) is the video system used in the FMF vault. For the test and evaluation of the MMIPS subsystem, a small subset of storage containers were selected for monitoring in the vault. The containers are monitored by four video cameras placed in predetermined locations. Any movement within the defined regions of interest results in PAMTRAK generating an alarm.

The FMF installation takes advantage of a PAMTRAK feature that allows multiple sensors monitoring the same material to be logically combined to generate a higher-priority alarm. For example, in the FMF several containers are being monitored by both a WATCH and the MMIPS VMD subsystem. If either subsystem detects movement associated with those containers, PAMTRAK reports a standard alarm that is handled by the system manager. However, if both a WATCH and the MMIPS report movement on the same container within a few seconds of each other, PAMTRAK reports a higher-priority alarm directly to the SPOs in the security building.

The Precision Tracking FM, Inc. system is used to track personnel within the FMF. Sensors at key entry points in the facility monitor and report the location of building personnel by detecting the tags mounted on the ARGUS badges. When personnel enter and move within the facility, their presence is detected by PAMTRAK. If personnel move into an unauthorized area, an alarm is generated by PAMTRAK.

Material movements between areas are performed by qualified fuel handlers through the use 
of programmable barcode readers and barcodes applied to all storage and transfer containers. Fuel handlers are granted access to the material by job levels assigned to a transaction type and by material access areas. These job levels and access areas are electronically administered and controlled by PAMTRAK.

To initiate a material movement a fuel handler enters the appropriate information to PAMTRAK using a barcode reader. As the barcode reader sends the information, PAMTRAK verifies the validity of the information. PAMTRAK validates access to established areas and types of material. If the worker requesting access to that material does not meet the material transfer requirements administered by PAMTRAK, permission is denied. If the requirements are met PAMTRAK grants permission and the transaction continues. However, the fuel handler still has the overall responsibility to ensure all procedures are followed. After the transaction is complete, PAMTRAK sends the transaction information to PC-DYMAC, the material control and accountability system.

\section{K-Reactor, Savannah River Site}

PAMTRAK, in conjunction with RandTec VersaTags, was installed at the Savannah River Site (SRS) K-Area. The main PAMTRAK computer is located in a computer room inside a storage area in the K-Reactor. It communicates directly with the VersaTag system. In addition to the main PAMTRAK computer, we have installed two auxiliary computers, one in the K-Reactor Entry Control Facility (ECF) and the other in the SRS administration area. These auxiliary computers allow users to remotely configure and control the main PAMTRAK computer via the site network. PAMTRAK also displays alarms on the auxiliary computers.

The VersaTags monitor tamper-indicating devices (TIDs) consisting of loops of optical fibers. They are installed on shipping containers housing special nuclear material (SNM) and also on storage racks containing SNM. Any attempt to disconnect or bend the fiber-optic loops is detected by the VersaTags and reported to PAMTRAK. By providing continuous material surveillance, the inventory period for the material can be extended from six months to one year, and the two-person rule and daily administrative check requirements can be relaxed.
Additional protection for the material is provided by the IVSystem using video motion detection. The two systems, PAMTRAK and IVSysten, when used together, ensure a low false alarm rate and provide a very high probability that any attempts to tamper with the material will be detected.

\section{BENEFITS}

Before the barcode readers were installed in the ANL-W FMF, all material movement required terminal keyboard entries by the fuel technicians. In using the barcode readers for material transfers, keyboard entry errors have been eliminated. By administering the two-person rule through PAMTRAK, the same fuel handlers must originate and complete a material transfer. This ensures the material is being transferred not only by qualified fuel handlers, but also by individuals who initiated and understand the operation.

Installing PAMTRAK at K-Reactor has allowed SRS to extend the inventory period for the material there from six months to one year. They can also relax the two-person rule and daily administrative checks that were previously required.

A surveillance system such as PAMTRAK can reduce the cost of storing material not only by reducing inventory frequency, but also by reducing radiation exposure to workers. This helps sites conform to the ALARA (As Low As Reasonably Achievable) principle. An analysis done at the Savannah River Site in 1992 estimated that installing a material monitoring system, such as PAMTRAK, in the seven active and future vaults at that site would save $\$ 1,073,000$ per year by reducing inventory frequency from once a month (which was mandated at that time) to once a year. ${ }^{2}$ This analysis did not take into account additional savings resulting from the relaxation of the two-person rule.

There are two notable drawbacks to relying exclusively on physical inventories to prove the integrity of stored material. The first is that material theft may not be detected until months after it has taken place, with little hope of recovery. PAMTRAK, since it is a real-time system, can detect theft or diversion soon enough to give the guard force a realistic chance of recovering the material and apprehending the perpetrator. The second drawback

\footnotetext{
${ }^{2}$ Internal DOE Memorandum from T. L. Williams to L. Brown.
} 
is that in performing an inventory, a site typically checks only a fraction of the material using random, statistical sampling methods. In contrast, PAMTRAK continuously monitors all material in the vault.

\section{SUMMARY}

PAMTRAK is a flexible, robust, and relatively inexpensive system for sites to install and maintain. A site can use any combination of a variety of subsystems to track personnel and monitor material. PAMTRAK includes remote control and alarm display capabilities, and a complementary program in Keyhole to display measured material attributes remotely.

\section{REFERENCES}

[1] Jonathan P. Anspach, "New PAMTRAK Video and Interface Capabilities", in proceedings from the 35th Annual Meeting of Nuclear Materials Management, July 17-20, 1994.

[2] Bruce Dahly and Jonathan Anspach, "New PAMTRAK Features", in proceedings from the 36th Annual Meeting of Nuclear Materials Management, July 9-12, 1995.

[3] Bruce Dahly and Gail Walters, "The PAMTRAK System and its Operational Issues", in proceedings from The 5th International Conference on Facility Operations Safeguards Interface, September 24-29, 1995.

\section{DISCLAIMER}

This report was prepared as an account of work sponsored by an agency of the United States Government. Neither the United States Government nor any agency thereof, nor any of their employees, makes any warranty, express or implied, or assumes any legal liability or responsibility for the accuracy, completeness, or usefulness of any information, apparatus, product, or process disclosed, or represents that its use would not infringe privately owned rights. Reference herein to any specific commercial product, process, or service by trade name, trademark, manufacturer, or otherwise does not necessarily constitute or imply its endorsement, recommendation, or favoring by the United States Government or any agency thereof. The views and opinions of authors expressed herein do not necessarily state or reflect those of the United States Government or any agency thereof. 